\title{
\begin{tabular}{l|l} 
Mitraries & DSpace@MIT
\end{tabular}
}

\author{
MIT Open Access Articles
}

\section{Phenotypic plasticity and epithelial-mesenchymal transitions in cancer and normal stem cells?}

The MIT Faculty has made this article openly available. Please share how this access benefits you. Your story matters.

Citation: Scheel, Christina, and Robert A. Weinberg. “Phenotypic Plasticity and EpithelialMesenchymal Transitions in Cancer and Normal Stem Cells?" International Journal of Cancer 129, no. 10 (August 29, 2011): 2310-2314 (C) 2011 UICC

As Published: http://dx.doi.org/10.1002/ijc.26311

Publisher: Wiley Blackwell

Persistent URL: http://hdl.handle.net/1721.1/116967

Version: Author's final manuscript: final author's manuscript post peer review, without publisher's formatting or copy editing

Terms of use: Creative Commons Attribution-Noncommercial-Share Alike 


\title{
Phenotypic Plasticity and Epithelial-Mesenchymal Transitions in Cancer - and Normal Stem Cells?
}

\author{
Christina Scheel ${ }^{1}$ and Robert A. Weinberg ${ }^{1,2,3}$ \\ ${ }^{1}$ Whitehead Institute for Biomedical Research, Cambridge, MA 02142, USA \\ ${ }^{2}$ Department of Biology, Massachusetts Institute of Technology, Cambridge, MA 02139, USA \\ ${ }^{3}$ MIT Ludwig Center for Molecular Oncology, Cambridge, MA 02139, USA
}

\section{Abstract}

Cancer stem cells (CSCs) are similar to normal stem cells in their ability to self-renew and to generate large populations of more differentiated descendants. In contrast to the hierarchical organization that is presumed to be the prevalent mode of normal tissue homeostasis, phenotypic plasticity allows cancer cells to dynamically enter into and exit from stem-cell states. The Epithelial-Mesenchymal Transition (EMT) has been closely associated with the acquisition of both invasive and stem-cell properties in cancer cells. Thereby, EMT programs emerge as important regulators of phenotypic plasticity in cancer cells including their entrance into stem-cell states. Much is still to be learned about the regulation of EMTs through epigenetic mechanisms in cancer cells and the contributions that EMT programs make to normal tissue homeostasis.

\section{Keywords}

Cancer stem cells; stem cells; tumor-initiating ability; self-renewal; epithelial-mesenchymal transition; multi-step progression; cellular state; phenotypic plasticity

\section{Concept and detection of cancer stem cells}

Despite ongoing debate about their existence and provenance, the discovery of cancer stem cells (CSCs) within tumors has provided an important conceptual framework that has proven highly useful for understanding intratumoral heterogeneity. ${ }^{1,2}$ CSCs are operationally defined through their ability to generate tumors with high efficiency when implanted in limiting dilution into immunocompromised host mice; implicit in their tumorigenic powers is an ability to self-renew, and to give rise to progeny that lack this ability. For a comprehensive review on methods to quantify CSCs, see Alison et al. ${ }^{3}$

Analogous to the unidirectional, cellular organization that has been associated with the cells in the bone marrow, CSCs are often described as cells sitting at the apex of a hierarchy, as defined by tumor-initiating potential. ${ }^{4}$ CSCs were prospectively isolated first from acute myeloid leukemias based on cell-surface marker expression ${ }^{5}$, and later in solid malignancies such as breast ${ }^{6}$, brain $^{7}$, colon $^{8,9}$ and pancreatic cancer. ${ }^{10}$

Importantly, the existing model of CSCs does not dictate that they invariably comprise only rare subpopulations within tumors. ${ }^{11}$ Instead, their representation within neoplastic cell populations may be affected by the genetic modifications that cancer cells have accumulated 
as well as a variety of contextual signals that such tumors experience in the tumor microenvironment. ${ }^{3}$ Furthermore, the quantification of CSCs in a population of tumor cells is never absolute, but instead depends on the precise specifications of the tumor-initiating assay used to test for their presence. Tumor-initiating rates of human melanoma cells have been shown to vary greatly in mouse strains with differing degrees of immunosuppression. ${ }^{12}$ Moreover, tumor-initiating assays used to quantify CSCs have also proven highly useful in gauging tumor aggressiveness and heterogeneity: recent evidence suggests that the aggressive clinical behavior of primary breast cancer samples can be correlated with their stem-cell content. ${ }^{13}$

\section{Cancer stem cells and multi-step tumor progression}

A major conceptual challenge has been to integrate the CSC model with the widely accepted clonal succession model of tumor progression first proposed by Nowell. ${ }^{14}$ In the latter, the multistep progression of tumors is said to reflect a sequence of clonal successions, each one of which is triggered by the acquisition of an advantageous mutation. Such a mutation confers on the mutant cell an ability to overgrow other cells in the neighborhood and ultimately to spawn a large cohort of descendants; in one of these descendants, yet another mutation occurs that triggers a new round of clonal expansion and succession. Altogether, half a dozen or more such clonal successions are likely to define the multi-step progression of common human tumors, each reflecting the acquisition of a critical genetic or heritable epigenetic change by the involved cells. ${ }^{15}, 16$

A simple model integrating CSCs and clonal succession proposes that normal stem cells (SCs) acquire an initial mutation and evolve into a mutant SC population; the latter continues to generate, like their normal SC precursors, more differentiated descendants (Figure 1a). Cells within the initially formed mutant SC population may then acquire yet another mutation and thereby evolve into an incrementally more neoplastic SC population. The end product of these multiple steps, in which one SC population evolves progressively into another, is a fully neoplastic SC, i.e., a CSC with tumor-initiating potential. Importantly, at each stage of tumor progression, a SC subpopulation of cells co-exists with their genetically identical, but more differentiated progeny. Hence, the hierarchy of SCs spawning non-SCs is reconstructed at each step of multi-step progression.

This model of one SC population evolving into CSCs is burdened by at least two major conceptual difficulties. First, the mutations that strike the preneoplastic SC populations (and subsequently their more neoplastic SC derivatives) occur at a low rate per cell generation, perhaps as low as one per million cell divisions. ${ }^{17}$ Such estimates have recently been substantiated by visualization of replication error mutations in live cells in vitro. ${ }^{18}$ These numbers create a major dilemma, since the overall size of each of these SC populations is relatively small, and the absolute number of SCs is therefore rather low. Stated differently, the size of the target cell populations in which mutations must strike is very small. Taken together with the generally low rate of mutation, this indicates that a mutation striking a SC population (at various stages of neoplastic progression) is a highly improbable event.

A second conceptual difficulty with the SC evolution model portrayed above derives from the biology of SCs: generally, they divide only occasionally, with the great bulk of the mitotic activity in normal (and likely neoplastic) tissues being exhibited by their more differentiated progenitor/transit-amplifying progeny. ${ }^{19,20}$ At the same time, it is known that mutations strike non-proliferating populations of cells very rarely, a consequence of the fact that many mutations are sustained as a consequence of replication errors including the replication of unrepaired DNA segments. ${ }^{21}$ Given the relatively low proliferation rate of $\mathrm{SCs}$, this makes them once again unlikely targets of the mutations that are likely to trigger 
the clonal successions that drive multistep tumor progression. Importantly, lineage tracing experiments suggest that some SCs, particularly in the intestine ${ }^{22}$, can shuttle between a quiescent and actively cycling state. Such "active SCs" have indeed been proposed as targets of transformation ${ }^{23}$.

\section{Generation of cancer stem cells through EMT}

These considerations force some revision of the hierarchical model of normal SC and CSC biology. Some insight comes from the recent discovery that epithelial-mesenchymal transitions (EMTs), which were thought to primarily convert epithelial cells (in various states of neoplastic transformation) into cells with mesenchymal attributes, additionally equip more differentiated epithelial cells with stem cell traits. ${ }^{24,25}$ This connection was most unexpected, indeed counterintuitive, as it indicated that various types of epithelial SCs express a wide array of mesenchymal markers. Importantly, these include a series of pleiotropically acting transcription factors (TFs) that are known to be capable, on their own, of inducing EMTs when expressed in epithelial cells. ${ }^{26,27}$ Recently, these EMT-inducing TFs have been molecularly linked to self-renewal programs, either through down regulation of stemness-repressing microRNAs ${ }^{28,29}$ or by directly inducing expression of Bmi-1, a component of the chromatin-remodeling polycomb repressor complex $1 .{ }^{30}$

Currently available evidence indicates that the EMT-SC connection applies to both normal epithelial cell populations as well as neoplastic cell populations, i.e., populations of carcinoma cells. ${ }^{24,28}$ It seems, therefore, that neoplastic cell populations do not invent a novel SC program to drive their sustained proliferation. Instead, they appear to adopt the SC program that was operative in more normal (or fully normal) antecedent cell populations and to exploit this program in order to organize the complex tissues observed at various stages of neoplastic progression.

This connection between EMT and epithelial SCs indicates that the EMT process is doubly dangerous for the cancer patient: By imparting mesenchymal traits to carcinoma cells, an EMT can confer cell-biological traits associated with high-grade malignancy, including motility, invasiveness and a resistance to apoptosis; these can lead in turn to metastatic dissemination from primary tumors. ${ }^{31}$ At the same time, by imparting the trait of selfrenewal to carcinoma cells, the EMT creates cancer cells that are qualified to seed the large colonies of cancer cells that form macroscopic metastases. ${ }^{32}$

The EMT may also provide a means to integrate the CSC model with multi-step tumorigenesis. Thus, it is apparent that contextual signals received from a reactive stroma $^{33,34}$ or hypoxia ${ }^{35}$ are able to induce carcinoma cells to undergo an EMT. By extension, such contextual signals originating in the tumor microenvironment should also be able to create new CSCs. Hence, in addition to CSCs differentiating into non-CSCs (the canonical CSC model), non-CSCs may be induced, under certain conditions, to dedifferentiate into CSCs, and this dedifferentiation may occur at various stages of malignant progression.

This ability to dedifferentiate makes it possible to reconcile the CSC and multi-step tumor progression models of tumor pathogenesis. In particular, it now becomes attractive to propose that the mutations driving multi-step tumor progression do not strike various SC populations, as indicated above. Instead, such mutations are far more likely to strike transitamplifying populations. The latter cell populations are far larger, yielding greatly increased numbers of cells that are targets of mutation; at the same time, these populations are generally highly proliferative, indeed representing the lion's share of the mitotic activity in most tissues. Accordingly, mutations that are first sustained in transit-amplifying/progenitor populations may then be introduced into the corresponding SC populations via an EMT- 
driven dedifferentiation process. Once present in the SC pool, such mutant cells can thereafter dominate this pool and generate the multitudinous progeny that, upon differentiation, manifest phenotypically the recently acquired mutant genotype (Figure 1b).

\section{Cancer stem cells and the development of effective therapeutics}

The existence of CSCs may also compromise the effectiveness of existing anti-cancer therapeutics and complicate the development of new ones. Thus, the clinical efficacy of therapeutics has traditionally been gauged by their ability to reduce or debulk tumor masses. Such reduction in overall tumor size has been perceived as a major step in preventing tumor progression, allowing extended progression-free survival and perhaps even eliciting durable responses that can be considered curative.

CSCs complicate these assessments of therapeutic success since they imply intratumoral biological heterogeneity. Thus, the distinct subpopulations within a tumor may respond differently to applied therapeutics because of differing sensitivities to the agents being used. If one population constitutes a small minority of cells in a tumor (e.g., CSCs), its behavior may not be gauged by measuring only the total mass of a tumor that has been exposed to one or another treatment. More ominously, if CSC populations are not eradicated when a tumor is being debulked, these residual surviving CSCs may then regenerate new tumor masses and thus, clinical relapses.

This is precisely what has emerged in recent years through studies of a variety of tumors and their responses to therapy. While the data are still fragmentary, it seems increasingly likely that various CSC subpopulations are more resistant to conventional therapeutic regimens relative to the majority populations of non-CSCs with which they co-exist. ${ }^{31,36}$ The mechanistic reasons for their increased resistance are still poorly understood. Nonetheless, the fact that they are indeed more resistant greatly complicates attempts at developing truly durable clinical responses if not cures.

These dynamics are illustrated by the action of the Bcr-Abl tyrosine kinase inhibitor Gleevec, which elicits excellent remission rates in patients with chronic myeloid leukemia (CML). However, even after years of treatment, a subpopulation of leukemic cells may persist, presumably containing CSCs, which give rise to clinical relapse in most patients who stop taking the drug. For a comprehensive review, see Rice et al. ${ }^{37}$ Indeed, relative resistance to apoptosis following a variety of insults, including standard chemotherapeutic drugs and radiation has emerged as a hallmark of CSCs. ${ }^{31,36}$

These considerations have forced the development of novel therapeutic strategies to screen for therapeutic agents that can eliminate the CSCs. Stated differently, such drugs may kill CSCs preferentially over non-CSCs. In one strategy, populations of CSCs generated by forcing breast cancer cells through an EMT have been used to screen for agents that preferentially kill these cells relative to their more differentiated non-CSC progeny. ${ }^{38}$ Alternatively, agents are being sought that in one fashion or another destabilize CSCs by affecting the specialized microenvironments in which they presumably reside within tumors. $^{39}$

\section{Cancer stem cells - hierarchical organisation vs. phenotypic plasticity}

Strategies to specifically target CSCs are complicated by recent lines of evidence suggesting that phenotypic plasticity exists in tumors that allows non-CSCs to acquire CSC traits and, thereby replenish the CSC pool (reviewed by Bomken). ${ }^{40}$ Indeed, malignant melanomas may represent the extreme end of such functional plasticity: recently, two studies suggested that reversible epigenetic regulatory mechanisms involving the H3K4 demethylase 
JARID1A ${ }^{41,42}$ allow melanoma cells to dynamically cycle between a tumor-initiating, CSCstate and a non-tumor initiating cellular state. Extensive transplantation experiments of primary, patient-derived melanoma cells lend further support to this model. ${ }^{43}$ When taken together, these lines of evidence do not refute the importance of stem cell traits for tumor biology, but replace a hierarchical, unidirectional model with one that accommodates dynamic regulation and the interconversion between alternative of cellular states.

Stated differently, the eradication of CSC subpopulations by agents that are targeted against them may in the future allow only a temporary clinical respite, as the surviving non-CSCs may, with a certain probability, dedifferentiate to generate new CSCs. This leads to yet another conclusion: Future durable therapeutic responses will need to target both the CSC and non-CSC populations within tumors. Whether this can be achieved by single agents or by pairs of agents, each directed toward one or the other cellular compartment, remains to be seen.

\section{Acknowledgments}

The authors thank Tom DiCesare (Whitehead Institute, Bioinformatics Group) for the figure and members of the Weinberg lab for fruitful discussion. Research in the Weinberg lab is supported by the NIH/NCI (R.A.W.: CA12515 and DE020817), MIT Ludwig Center for Molecular Oncology (R.A.W.), Ludwig Fellowship for Metastasis Research (C.S.), Breast Cancer Research Foundation (R.A.W.), Harvard Breast Cancer SPORE (R.A.W.) and DoD BCRP Idea Award (R.A.W.).

\section{References}

1. Shackleton M, Quintana E, Fearon ER, Morrison SJ. Heterogeneity in cancer: cancer stem cells versus clonal evolution. Cell. 2009; 138:822-9. [PubMed: 19737509]

2. Marotta LL, Polyak K. Cancer stem cells: a model in the making. Curr Opin Genet Dev. 2009; 19:44-50. [PubMed: 19167210]

3. Alison MR, Lim SM, Nicholson LJ. Cancer stem cells: problems for therapy? J Pathol. 2010

4. O’Brien CA, Kreso A, Jamieson CH. Cancer stem cells and self-renewal. Clin Cancer Res. 2010; 16:3113-20. [PubMed: 20530701]

5. Lapidot T, Sirard C, Vormoor J, Murdoch B, Hoang T, Caceres-Cortes J, Minden M, Paterson B, Caligiuri MA, Dick JE. A cell initiating human acute myeloid leukaemia after transplantation into SCID mice. Nature. 1994; 367:645-8. [PubMed: 7509044]

6. Al-Hajj M, Wicha MS, Benito-Hernandez A, Morrison SJ, Clarke MF. Prospective identification of tumorigenic breast cancer cells. Proc Natl Acad Sci U S A. 2003; 100:3983-8. [PubMed: 12629218]

7. Singh SK, Hawkins C, Clarke ID, Squire JA, Bayani J, Hide T, Henkelman RM, Cusimano MD, Dirks PB. Identification of human brain tumour initiating cells. Nature. 2004; 432:396-401. [PubMed: 15549107]

8. O'Brien CA, Pollett A, Gallinger S, Dick JE. A human colon cancer cell capable of initiating tumour growth in immunodeficient mice. Nature. 2007; 445:106-10. [PubMed: 17122772]

9. Ricci-Vitiani L, Lombardi DG, Pilozzi E, Biffoni M, Todaro M, Peschle C, De Maria R. Identification and expansion of human colon-cancer-initiating cells. Nature. 2007; 445:111-5. [PubMed: 17122771]

10. Hermann PC, Huber SL, Herrler T, Aicher A, Ellwart JW, Guba M, Bruns CJ, Heeschen C. Distinct populations of cancer stem cells determine tumor growth and metastatic activity in human pancreatic cancer. Cell Stem Cell. 2007; 1:313-23. [PubMed: 18371365]

11. Kennedy JA, Barabe F, Poeppl AG, Wang JC, Dick JE. Comment on "Tumor growth need not be driven by rare cancer stem cells". Science. 2007; 318:1722. author reply. [PubMed: 18079385]

12. Quintana E, Shackleton M, Sabel MS, Fullen DR, Johnson TM, Morrison SJ. Efficient tumour formation by single human melanoma cells. Nature. 2008; 456:593-8. [PubMed: 19052619] 
13. Pece S, Tosoni D, Confalonieri S, Mazzarol G, Vecchi M, Ronzoni S, Bernard L, Viale G, Pelicci PG, Di Fiore PP. Biological and molecular heterogeneity of breast cancers correlates with their cancer stem cell content. Cell. 2010; 140:62-73. [PubMed: 20074520]

14. Nowell PC. The clonal evolution of tumor cell populations. Science. 1976; 194:23-8. [PubMed: 959840]

15. Cho KR, Vogelstein B. Genetic alterations in the adenoma--carcinoma sequence. Cancer. 1992; 70:1727-31. [PubMed: 1516027]

16. Meyerson M, Gabriel S, Getz G. Advances in understanding cancer genomes through secondgeneration sequencing. Nat Rev Genet. 2010; 11:685-96. [PubMed: 20847746]

17. Drake JW, Charlesworth B, Charlesworth D, Crow JF. Rates of spontaneous mutation. Genetics. 1998; 148:1667-86. [PubMed: 9560386]

18. Elez M, Murray AW, Bi LJ, Zhang XE, Matic I, Radman M. Seeing mutations in living cells. Curr Biol. 2010; 20:1432-7. [PubMed: 20674359]

19. Cotsarelis G, Sun TT, Lavker RM. Label-retaining cells reside in the bulge area of pilosebaceous unit: implications for follicular stem cells, hair cycle, and skin carcinogenesis. Cell. 1990; 61:1329-37. [PubMed: 2364430]

20. Arai F, Hirao A, Ohmura M, Sato H, Matsuoka S, Takubo K, Ito K, Koh GY, Suda T. Tie2/ angiopoietin-1 signaling regulates hematopoietic stem cell quiescence in the bone marrow niche. Cell. 2004; 118:149-61. [PubMed: 15260986]

21. Loeb LA, Cheng KC. Errors in DNA synthesis: a source of spontaneous mutations. Mutat Res. 1990; 238:297-304. [PubMed: 2188126]

22. Barker N, van Es JH, Kuipers J, Kujala P, van den Born M, Cozijnsen M, Haegebarth A, Korving J, Begthel H, Peters PJ, Clevers H. Identification of stem cells in small intestine and colon by marker gene Lgr5. Nature. 2007; 449:1003-7. [PubMed: 17934449]

23. Li L, Clevers H. Coexistence of quiescent and active adult stem cells in mammals. Science. 2010; 327:542-5. [PubMed: 20110496]

24. Mani SA, Guo W, Liao MJ, Eaton EN, Ayyanan A, Zhou AY, Brooks M, Reinhard F, Zhang CC, Shipitsin M, Campbell LL, Polyak K, et al. The epithelial-mesenchymal transition generates cells with properties of stem cells. Cell. 2008; 133:704-15. [PubMed: 18485877]

25. Morel AP, Lievre M, Thomas C, Hinkal G, Ansieau S, Puisieux A. Generation of breast cancer stem cells through epithelial-mesenchymal transition. PLoS ONE. 2008; 3:e2888. [PubMed: 18682804]

26. Acloque H, Adams MS, Fishwick K, Bronner-Fraser M, Nieto MA. Epithelial-mesenchymal transitions: the importance of changing cell state in development and disease. J Clin Invest. 2009; 119:1438-49. [PubMed: 19487820]

27. Thiery JP, Acloque H, Huang RY, Nieto MA. Epithelial-mesenchymal transitions in development and disease. Cell. 2009; 139:871-90. [PubMed: 19945376]

28. Shimono Y, Zabala M, Cho RW, Lobo N, Dalerba P, Qian D, Diehn M, Liu H, Panula SP, Chiao E, Dirbas FM, Somlo G, et al. Downregulation of miRNA-200c links breast cancer stem cells with normal stem cells. Cell. 2009; 138:592-603. [PubMed: 19665978]

29. Wellner U, Schubert J, Burk UC, Schmalhofer O, Zhu F, Sonntag A, Waldvogel B, Vannier C, Darling D, zur Hausen A, Brunton VG, Morton J, et al. The EMT-activator ZEB1 promotes tumorigenicity by repressing stemness-inhibiting microRNAs. Nat Cell Biol. 2009; 11:1487-95. [PubMed: 19935649]

30. Yang MH, Hsu DS, Wang HW, Wang HJ, Lan HY, Yang WH, Huang CH, Kao SY, Tzeng CH, Tai SK, Chang SY, Lee OK, et al. Bmil is essential in Twist1-induced epithelial-mesenchymal transition. Nat Cell Biol. 2010; 12:982-92. [PubMed: 20818389]

31. Singh A, Settleman J. EMT, cancer stem cells and drug resistance: an emerging axis of evil in the war on cancer. Oncogene. 2010; 29:4741-51. [PubMed: 20531305]

32. Brabletz T, Jung A, Spaderna S, Hlubek F, Kirchner T. Opinion: migrating cancer stem cells - an integrated concept of malignant tumour progression. Nat Rev Cancer. 2005; 5:744-9. [PubMed: 16148886]

33. Kirchner T, Brabletz T. Tumor patterning: analogies of neoplastic morphogenesis with embryogenesis. Verh Dtsch Ges Pathol. 2000; 84:22-7. [PubMed: 11217443] 
34. Giehl K, Menke A. Microenvironmental regulation of E-cadherin-mediated adherens junctions. Front Biosci. 2008; 13:3975-85. [PubMed: 18508491]

35. Yang MH, Wu MZ, Chiou SH, Chen PM, Chang SY, Liu CJ, Teng SC, Wu KJ. Direct regulation of TWIST by HIF-1alpha promotes metastasis. Nat Cell Biol. 2008; 10:295-305. [PubMed: 18297062]

36. Diehn M, Cho RW, Clarke MF. Therapeutic implications of the cancer stem cell hypothesis. Semin Radiat Oncol. 2009; 19:78-86. [PubMed: 19249645]

37. Rice KN, Jamieson CH. Molecular pathways to CML stem cells. Int J Hematol. 2010; 91:748-52. [PubMed: 20533007]

38. Gupta PB, Onder TT, Jiang G, Tao K, Kuperwasser C, Weinberg RA, Lander ES. Identification of Selective Inhibitors of Cancer Stem Cells by High-Throughput Screening. Cell. 2009

39. Zhao C, Chen A, Jamieson CH, Fereshteh M, Abrahamsson A, Blum J, Kwon HY, Kim J, Chute JP, Rizzieri D, Munchhof M, VanArsdale T, et al. Hedgehog signalling is essential for maintenance of cancer stem cells in myeloid leukaemia. Nature. 2009; 458:776-9. [PubMed: 19169242]

40. Bomken S, Fiser K, Heidenreich O, Vormoor J. Understanding the cancer stem cell. Br J Cancer. 2010; 103:439-45. [PubMed: 20664590]

41. Sharma SV, Lee DY, Li B, Quinlan MP, Takahashi F, Maheswaran S, McDermott U, Azizian N, Zou L, Fischbach MA, Wong KK, Brandstetter K, et al. A chromatin-mediated reversible drugtolerant state in cancer cell subpopulations. Cell. 2010; 141:69-80. [PubMed: 20371346]

42. Roesch A, Fukunaga-Kalabis M, Schmidt EC, Zabierowski SE, Brafford PA, Vultur A, Basu D, Gimotty P, Vogt T, Herlyn M. A temporarily distinct subpopulation of slow-cycling melanoma cells is required for continuous tumor growth. Cell. 2010; 141:583-94. [PubMed: 20478252]

43. Quintana E, Shackleton M, Foster HR, Fullen DR, Sabel MS, Johnson TM, Morrison SJ. Phenotypic Heterogeneity among Tumorigenic Melanoma Cells from Patients that Is Reversible and Not Hierarchically Organized. Cancer Cell. 2010; 18:510-23. [PubMed: 21075313] 


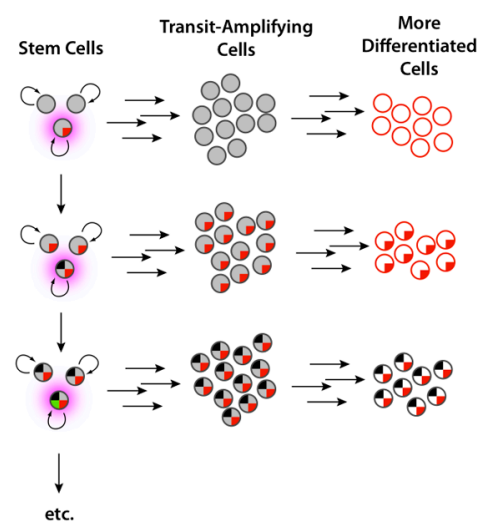

b

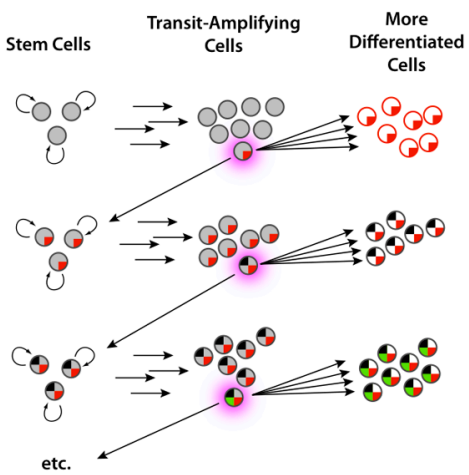

Figure 1. Multi-step progression of cancer and the cancer stem cell (CSC) model Adapted from Weinberg RA., "The Biology of Cancer", Garland Science. (a) Normal stem cells (SCs) acquire an initial mutation and evolve into a mutant SC population (cells of different cellular states are depicted as circles, mutational events are indicated by pink halo; cells carrying a specific mutations are indicated by colored quarter within "cells"); the latter continues to generate, more differentiated descendants carrying that mutation. Cells within the initially formed mutant SC population acquire another mutation and evolve into an incrementally more neoplastic SC population. The end product is a CSC with tumorinitiating potential. (b) The mutations driving multi-step tumor progression do not strike various SC populations, as indicated above, but strike transit-amplifying populations that are introduced into the corresponding SC populations via a dedifferentiation process. 